\title{
Neutrophil activation in fibrosing alveolitis: a comparison of lone cryptogenic fibrosing alveolitis and systemic sclerosis
}

\author{
J.B. Cailes*, C. O'Connor**, P. Pantelidis*, A.M. Southcott*, M.X. Fitzgerald**, \\ C.M. Black+, R.M. du Bois*
}

Neutrophil activation in fibrosing alveolitis: a comparison of lone cryptogenic fibrosing alveolitis and systemic sclerosis. J.B. Cailes, C. O'Connor, P. Pantelidis, A.M. Southcott, M.X. Fitzgerald, C.M. Black, R.M. du Bois. (CERS Journals Ltd 1996.

ABSTRACT: Fibrosing alveolitis complicating systemic sclerosis (FASSc) carries a better prognosis than lone cryptogenic fibrosing alveolitis (CFA). We wanted to determine whether this improved prognosis is associated with differential neutrophil migration and activation in the lower respiratory tract.

We therefore compared bronchoalveolar lavage (BAL) neutrophil numbers and levels of neutrophil-derived enzymes in FASSc, CFA and normal individuals. Bronchoalveolar lavage was performed on 45 subjects (FASSc $n=20$; CFA $n=15$; normals $n=10$ ); cell counts and levels of neutrophil-derived enzymes, myeloperoxidase, elastase (total elastase and elastase $/ \alpha_{1}$-antitrypsin complexes), collagenase and lactoferrin were measured. Lung function testing was performed in subjects with fibrosing alveolitis.

Significant differences in the levels of collagenase, myeloperoxidase and elastase/ $\alpha_{1}$-antitrypsin complexes were present in the BAL fluid from the three groups. Patients with CFA had significantly higher neutrophil percentages and levels of collagenase and myeloperoxidase than those with FASSc. Disease extent, as judged by lung volumes and gas transfer, was comparable in the CFA and FASSc groups. Forced vital capacity (\% predicted) was significantly lower in patients with evidence of increased neutrophil enzyme release than those without.

We conclude that: 1) increased neutrophil migration to the lung is accompanied by release both of primary and secondary granule enzymes in cryptogenic fibrosing alveolitis; and 2) the lower amounts of neutrophil products in fibrosing alveolitis complicating systemic sclerosis may account for the improved prognosis, even when disease is as extensive as in cryptogenic fibrosing alveolitis.

Eur Respir J., 1996, 9, 992-999.

\author{
*Royal Brompton Hospital, London, UK. \\ **University College, Dublin, Ireland. \\ +Royal Free Hospital, London, UK. \\ Correspondence: R.M. du Bois \\ Royal Brompton Hospital \\ Sydney St \\ London \\ SW3 6NP \\ UK \\ Keywords: Bronchoalveolar lavage \\ fibrosing alveolitis \\ neutrophil enzymes \\ systemic sclerosis
}

Received: December 211994 Accepted after revision January 211996

This study was supported by a grant from the Raynaud's and Scleroderma Association UK.
Fibrosing alveolitis (FA) can occur as a lone phenomenon (cryptogenic fibrosing alveolitis; CFA) or in association with rheumatological diseases, such as systemic sclerosis (FASSc). In these conditions neutrophils are found in increased numbers in bronchoalveolar lavage (BAL) fluid. Increased BAL neutrophil numbers are associated with extensive disease [1] and poor prognosis [2-4]. Neutrophil chemoattractants and activators have been shown to be present in BAL fluid of patients with CFA [5-8], and we have recently demonstrated that BAL fluid from patients with FASSc contains increased interleukin-8 (IL-8) by comparison with controls, but significantly less than CFA [9]. The neutrophil is thought to cause damage to pulmonary parenchyma through the release of proteolytic enzymes from neutrophil granules and from the generation of oxygen-derived radicals [10].

The histopathological appearance of CFA is identical to that seen in FASSc [11]. Despite these histological similarities, however, the two diseases have a strikingly different prognosis with respect to survival. It has been demonstrated that the actuarial survival of patients with FASSc is greater than CFA, when patients are matched for demographic factors, disease extent and smoking history [12]. The explanation for the differences in actuarial survival have yet to be established but, in the context of the knowledge that: 1) increased percentages of neutrophils on the epithelial surface of the lungs are associated with more extensive disease on computed tomography (CT) and with a poorer outlook; 2) neutrophil products probably play a significant role in perpetuating lung injury; and 3) different amounts of the potent neutrophil chemoattractant IL-8 are present in the lungs of patients with CFA compared with FASSc, we hypothesized that a differential pattern of neutrophil influx and degranulation might be central to the differences in survival. Free neutrophil enzymes, such as collagenase and myeloperoxidase (MPO), are known to be present in increased amounts in BAL fluid of patients with CFA in comparison with normal individuals [13, 14].

The relative activity of BAL fluid neutrophil granular enzymes in CFA and FASSc has not previously been evaluated. To answer this question we therefore quantified the activity of enzymes both from primary and secondary neutrophil granules in BAL fluid from patients with CFA and patients with FASSc and compared them 
to normal individuals. We further examined the relationships between the concentrations of these enzymes and lung function, smoking and treatment status. In CFA there was evidence of release of enzymes both from primary and secondary neutrophil granules. Significantly more MPO and collagenase was present in BAL fluid from patients with CFA than patients with FASSc with a similar physiological extent of disease. Enzyme levels in patients with FASSc were similar to those found in normal individuals, with the exception of raised levels of elastase bound to alpha ${ }_{1}$-antitrypsin (E-AT). The improved prognosis seen in patients with FASSc may be related to a relative decrease in neutrophil activation and enzyme release.

\section{Methods}

\section{Patients}

BAL samples were examined for neutrophil enzymes in 45 subjects (FASSc $n=20$; CFA $n=15$; controls $n=10$ ). The preliminary criteria of the American Rheumatism Association were used to define patients with systemic sclerosis [15]. Criteria for the diagnosis of CFA were: 1) bilateral basal or widespread crackles on auscultation of the chest; 2) pulmonary function tests showing a restrictive ventilatory defect or depression of total gas transfer; 3) appearances on thin section CT compatible with CFA and/or open lung biopsy; and 4) exclusion of other causes of FA. Controls were normal individuals with no evidence of lung disease. Demographic data are summarized in table 1 . Subjects with CFA were older than those with FASSc, both groups being older than controls $(p<0.05)$. Subjects with CFA were more likely to be male and to have been past smokers. The number of active smokers at the time of the BAL did not, however, differ significantly between the groups.

\section{Analysis of BAL fluids for neutrophil activation markers}

BAL fluids were analysed for the primary granule enzymes, elastase (total elastase and elastase $/ \alpha_{1}$-antitrypsin complexes) and MPO, and the secondary granule

Table 1. - Demographic and clinical characteristics of the three groups studied

\begin{tabular}{lcccc}
\hline & Normal & CFA & FASSc & p-value \\
\hline Subjects n & 10 & 15 & 20 & \\
Age yrs & $24(4.6)$ & $60(6)$ & $45(11.4)$ & $<0.001$ \\
Sex M/F & $6 / 4$ & $13 / 2$ & $6 / 14$ & $<0.01$ \\
Current smokers n & 0 & 3 & 1 & NS \\
Ex-smokers\# n & 0 & 10 & 6 & $<0.05$ \\
$\begin{array}{l}\text { Pack-years smoked } \\
\text { Active treatment }\end{array}$ & 0 & $28(17)$ & $2(4)$ & $<0.001$ \\
$\quad$ NA & $6 / 15$ & $10 / 20$ & NS \\
CT fime of BAL \#\# & & & & \\
\hline
\end{tabular}

Values are expressed as mean and SD in parenthesis. Normal: control subjects with no evidence of lung disease; CFA: cryptogenic fibrosing alveolitis; FASSc: fibrosing alveolitis associated with systemic sclerosis; NA: not applicable; CT fibrosing alveolitis: computed tomography pattern consistent with fibrosing alveolitis; BAL: bronchoalveolar lavage; NS: nonsignificant. \#: past smokers with at least 6 months abstinence prior to BAL; \#\#: the use of either prednisolone or immunosuppressive medications at the time of BAL. enzymes collagenase and lactoferrin (LF). Before analysis, aliquots of lavage fluid were centrifuged at $1,000 \times \mathrm{g}$ for $15 \mathrm{~min}$ and phenylmethylsuphonyl fluoride (PMSF), final concentration $0.1 \mathrm{mM}$, was added to prevent postsampling protease digestion. For collagenase determination, samples were concentrated 20 fold by ultrafiltration in CF25 Centriflo membrane cones (Amicon Corp., Danvers, USA). Radioimmunodiffusion (RID) plates (LCPartigen; Behringwerke AG, Marburg, Germany) were used to determine BAL albumin levels.

Myeloperoxidase. Neutrophil MPO activity was measured by assessing the oxidation of 4-aminoantipyrine in the presence of hydrogen peroxide, using a modification of the method described by MetCaLf et al. [16]. The assay was performed on 96-well plates containing $50 \mu \mathrm{L}$ of freshly prepared 4-aminoantipyrine: $\mathrm{H}_{2} \mathrm{O}_{2}$ substrate and $50 \mu \mathrm{L}$ of BAL sample. Following incubation for $15 \mathrm{~min}$, the reaction was stopped by the addition of $100 \mu \mathrm{L}$ of $0.1 \mathrm{M}$ sodium acetate buffer ( $\mathrm{pH}$ 3.0). A sample control, to which sodium acetate buffer was added at time zero, was prepared for each sample. The difference in absorbance at $490 \mathrm{~nm}$ between test and control samples was used to calculate MPO units, defined as change in absorbance $\cdot \mathrm{min}^{-1} \cdot \mathrm{mL}^{-1}$.

Elastase. Total neutrophil elastase (NE) was assessed by indirect enzyme-linked immunosorbent assay (ELISA) as described previously [17]. Briefly, 96-well microtitre plates were coated with purified NE for $48 \mathrm{~h}$ at $4{ }^{\circ} \mathrm{C}$, blocked with $1 \%$ bovine serum albumin (BSA) in phosphate-buffered saline (PBS) and washed with PBS containing $0.1 \%$ Tween ${ }^{\circledR} 20$. Triplicate aliquots of samples and standards, preincubated with sheep antihuman NE (Serotech, Oxford, UK) for $2 \mathrm{~h}$ at $37^{\circ} \mathrm{C}$ were then added to the precoated microtitre plate. Processing of the plates using rabbit anti-sheep immunoglobulin G (IgG) (Sigma, Poole, Dorset, UK) followed by horseradish peroxidaseconjugated goat anti-rabbit IgG (Promega, Madison, WI.) was carried out using standard methods. Assessment of this assay in the presence of serum $\alpha_{1}$-antitrypsin and $\alpha_{2}$-macroglobulin indicates that both free $\mathrm{NE}$ and $\mathrm{NE}$ bound to these inhibitors are detected.

Elastase $/ \alpha_{1}$-antitrypsin complexes. Elastase $/ \alpha_{1}$-antitrypsin complexes were measured by a double ligand ELISA available from Merck (Darmstadt, Germany) on a randomly selected subset of samples from each group (normal controls $n=5$; CFA $n=6$; FASSc $n=12$ ). Samples were added to plastic tubes coated with anti-NE antibody and incubated at $20^{\circ} \mathrm{C}$ for $1 \mathrm{~h}$. An alkaline phosphatase conjugated antibody to $\alpha_{1}$-antitrypsin was then added and incubated at $20^{\circ} \mathrm{C}$ for $30 \mathrm{~min}$. Following washing to remove excess antibody, the enzyme activity of the complexed alkaline phosphatase was measured photometrically using 4-nitrophenyl phosphate as substrate.

Collagenase. Collagenase activity was determined by measuring the release of radiolabelled fragments from type 1 collagen. Substrate was prepared by labelling type 1 acid soluble calf skin collagen (Sigma, Poole, Dorset, UK) with $\left[1-{ }^{14} \mathrm{C}\right]$ acetic anhydride [18]. Prior to each assay, activation of latent collagenase was carried 
out by preincubating BAL samples with $1 \mathrm{mM}$ p-aminophenylmercuric acetate (APMA) for $10 \mathrm{~min}$ at $35^{\circ} \mathrm{C}$. Labelled substrate $(20,000-30,000$ counts per minute (cpm) per $100 \mu \mathrm{L}$ and at a concentration of $1.0-1.2 \mathrm{mg} \cdot \mathrm{mL}^{-1}$ ) in $0.05 \mathrm{M}$ Tris buffer containing $0.05 \mathrm{M} \mathrm{CaCl}_{2}$ and 0.2 $\mathrm{M} \mathrm{NaCl}(\mathrm{pH} 7.5)$ was incubated with $100 \mu \mathrm{L}$ sample for $90 \mathrm{~min}$ at $35^{\circ} \mathrm{C}$. The reaction was terminated by the addition of $100 \mu \mathrm{L}$ of $0.1 \mathrm{M}$ ethylenediamine tetra-acetic acid (EDTA) and $100 \mu \mathrm{g}$ of unlabelled collagen $\left(2 \mathrm{mg} \cdot \mathrm{mL}^{-1}\right)$. Incubation was continued for a further $30 \mathrm{~min}$ to allow complete denaturation of the cleaved fragments. Four hundred microlitres of dioxane: methanol:water (4:1:5 volume) was then added to precipitate undigested collagen and the samples centrifuged at $2,500 \times \mathrm{g}$ for $1 \mathrm{~h}$ to sediment the undigested substrate. The supernatant containing the digested collagen fragments was counted in a liquid scintillation counter (Beckman Rack beta, Model 127-001) after the addition of Ecolite scintillation fluid. Samples were assayed in duplicate and a control, to which EDTA and unlabelled collagen were added before incubation, was included for each sample. The difference in counts between test and control samples was used to calculate units of collagenase activity as being micrograms of collagen degraded $\cdot \mathrm{min}^{-1} \cdot \mathrm{mL}^{-1}$ of BAL.

Lactoferrin levels. Analysis of BAL LF levels was carried out using a modification of the ELISA system described by Kolsto-Otnaess et al. [19]. Briefly, 96well microtitre plates were coated for $24 \mathrm{~h}$ at $4^{\circ} \mathrm{C}$ with rabbit antihuman LF antibody (Sigma Chemical Co., Poole, Dorset, UK) diluted 1:1,000 in 0.05 M sodium carbonate buffer, $\mathrm{pH}$ 9.6. Wells were then blocked with $1 \%$ bovine serum albumin in PBS and washed with PBS containing $0.1 \%$. Tween ${ }^{\circledR} 20$. Samples and standards $(100 \mu \mathrm{L})$ were added to triplicate wells and incubated at $37^{\circ} \mathrm{C}$ for $90 \mathrm{~min}$. Processing of the plates with horse radish peroxidase conjugated with goat anti-human LF(Sigma Chemical Co.) was carried out using standard methods.

\section{Pulmonary function testing}

Pulmonary function tests were performed in the Lung Function Laboratory at the Royal Brompton Hospital. In all cases, pulmonary function tests were performed prior to BAL at the same visit. Forced vital capacity (FVC) was measured using a dry rolling seal spirometer (PK Morgan Ltd, Gillingham, UK). The transfer factor of the lungs for carbon monoxide (TL,CO) was measured by means of a rebreathing manoeuvre using modified [20] transfer factor equipment (PK Morgan Ltd), and data amended to a $10 \mathrm{~s}$ single breath result.

\section{Bronchoalveolar lavage}

Fibreoptic bronchoscopy and BAL were carried out using a standardized technique. Briefly, $100 \mathrm{~mL}$ of $0.9 \%$ saline was instilled into a subsegmental bronchus of each of the right middle and lower lobes and the lingula and retrieved by gentle hand suction. The lavage was collected in a siliconized container kept on ice. All manipulations were performed at $4^{\circ} \mathrm{C}$. The lavage was separated into cellular and supernatant (BAL fluid) fractions by centrifugation $(400 \times \mathrm{g}, 10 \mathrm{~min}$ ) (Sorvall RT6000B, Dupont, Stevenage, UK). BAL fluid was stored at $-80^{\circ} \mathrm{C}$ until enzyme analysis. Total BAL cells were counted and following cytospin preparation, differential cell counts were performed on at least 200 cells.

\section{Data analysis}

Data are presented as either mean (SD) if normally distributed or as median (range) if not. Comparisons between more than two groups were made by Kruskal Wallis nonparametric analysis of variance, whilst comparisons between two groups were made with the Mann-Whitney U-test. Correlations were analysed by Spearman's rank correlation. Multiple linear regression analysis was used to assess the relationship between neutrophil enzyme release and lung function indices, with patient age, sex, disease, duration of dyspnoea and pack-years smoked as independent covariates. In all tests a p-value of 0.05 was taken as representing significance.

\section{Results}

To assess the comparability of the patients with CFA and FASSc clinical characteristics at the time of the lavage were compared. All subjects had evidence of fibrosis on CT scanning. In the fibrosis groups, disease extent, judged by depression of lung function indices, was similar (fig. 1) (FVC, $\mathrm{p}=0.47 ; D \mathrm{~L}, \mathrm{CO}, \mathrm{p}=0.13$ ). The numbers of patients on treatment for FA (considered as the use of prednisolone with or without immunosuppressive therapy, such as azathioprine or cyclophosphamide, at the time of the BAL) were similar in the two groups.

\section{Cellular components of BAL}

Neutrophils and other inflammatory cells have the potential to damage pulmonary parenchyma. To ascertain

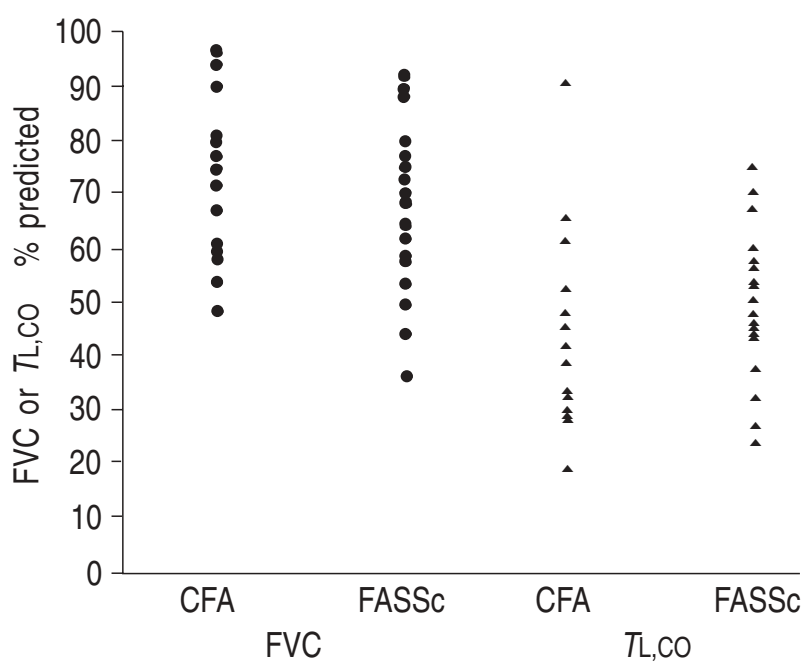

Fig. 1. - Forced vital capacity (FVC) and transfer factor of the lung for carbon monoxide ( $T \mathrm{~L}, \mathrm{CO}$ ) expressed as percentage of predicted value for patients with FASSc and CFA. The two groups of patients with fibrosing alveolitis have a similar physiological extent of disease as judged by lung function indices. CFA: cryptogenic fibrosing alveolitis; FASSc: fibrosing alveolitis associated with systemic sclerosis; $\%$ pred: percentage of predicted value. 
Table 2. - Bronchoalveolar lavage total and differential cell counts

\begin{tabular}{|c|c|c|c|c|c|c|}
\hline & \multicolumn{2}{|c|}{ Controls } & \multicolumn{2}{|c|}{ CFA } & \multicolumn{2}{|c|}{ FASSc } \\
\hline & $\%$ & Total & $\%$ & Total & $\%$ & Total \\
\hline Total cells & & $\begin{array}{c}1.73 \\
(0.6-2.4)\end{array}$ & & $\begin{array}{c}2.13 \\
(0.4-9.2)\end{array}$ & & $\begin{array}{c}2.48^{*} \\
(0.9-7.8)\end{array}$ \\
\hline Neutrophils & $\begin{array}{c}1 \\
(0-2)\end{array}$ & $\begin{array}{c}0.02 \\
(0-4.54)\end{array}$ & $\begin{array}{l}13.5^{\dagger \ddagger} \\
(1-60)\end{array}$ & $\begin{array}{c}0.23^{\dagger} \\
(0.01-3.51)\end{array}$ & $\begin{array}{c}3.0^{\dagger} \\
(0-24)\end{array}$ & $\begin{array}{c}0.09 \dagger \\
(0-1.25)\end{array}$ \\
\hline Lymphocytes & $\begin{array}{c}7.5 \\
(2-14)\end{array}$ & $\begin{array}{c}0.11 \\
(0.02-0.31)\end{array}$ & $\begin{array}{c}5.5 \\
(2-38)\end{array}$ & $\begin{array}{c}0.1 \\
(0.02-1.2)\end{array}$ & $\begin{array}{c}6 \\
(1-61)\end{array}$ & $\begin{array}{c}0.13 \\
(0.02-1.09)\end{array}$ \\
\hline Macrophages & $\begin{array}{c}91 \\
(85-98)\end{array}$ & $\begin{array}{c}1.56 \\
(0.54-2.1)\end{array}$ & $\begin{array}{c}74.5^{*} \\
(38-94)\end{array}$ & $\begin{array}{c}1.45 \\
(0.27-5.0)\end{array}$ & $\begin{array}{c}85^{*} \\
(39.5-95)\end{array}$ & $\begin{array}{c}2.16 \\
(0.67-6.3)\end{array}$ \\
\hline Eosinophils & $\begin{array}{c}0 \\
(0-4)\end{array}$ & $\begin{array}{c}0 \\
(0-0.1)\end{array}$ & $\begin{array}{c}3.0^{*} \\
(0-10)\end{array}$ & $\begin{array}{c}0.05^{*} \\
(0-0.28)\end{array}$ & $\begin{array}{c}1 \\
(0-15)\end{array}$ & $\begin{array}{c}0.02 * \\
(0-0.38)\end{array}$ \\
\hline
\end{tabular}

Values are expressed as median and range in parenthesis. Total cell count $\left(\times 10^{7}\right)$. For abbreviations see legend to table 1. *: $\mathrm{p}<0.05, \mathrm{CFA} / \mathrm{FASSc} v s$ control; $\uparrow: \mathrm{p}<0.001$, CFA/FASSc $v s$ control; $\ddagger: \mathrm{p}<0.05$, CFA vs FASSc.

whether there were significant differences in the number of inflammatory cells residing in the peripheral lung in the three groups, total and percentage cell counts were performed (table 2). Total cell numbers were similar in CFA and FASSc, and both were higher than controls. Both the percentage and total counts of neutrophils differed between the fibrosis and control groups ( $\mathrm{p}=0.001)$. CFA patients had higher neutrophil percentage counts than FASSc $(\mathrm{p}<0.05)$. Eosinophils numbers were increased in both fibrosing alveolitis groups by comparison with controls. No differences were found in the lymphocyte number. Percentage lavage fluid recovery was similar for all groups: CFA median (range) 50 (33-62)\%; FASSc 50 (33-77)\%; control 46 (33-73)\% (data not shown).

BAL profiles of primary and secondary neutrophil granular enzymes

To assess if there were differences in pulmonary neutrophil activity between the three groups, the activity in lavage fluid of enzymes originating both from primary and secondary neutrophil granules were compared. Though no fully satisfactory method of normalizing BAL fluid components is currently available [21], levels of neutrophil activation markers were calculated per microgram of albumin and comparisons repeated. Differences between the three groups were seen with respect to the activity of MPO (contained in primary granules) and collagenase (contained in secondary granules).

Primary granules. MPO activity was detected in $27 \%$ (4 out of 15) of samples from CFA patients (range 0-3.8 units) but in no samples from either FASSc or control patients $(\mathrm{p}=0.014)$. CFA patients had higher MPO levels than FASSc $(\mathrm{p}=0.016)$. Elastase activity did not differ between the three groups (CFA median (range) 90 (11-920) ng. $\mathrm{mL}^{-1}$; FASSc 106 (3-263) ng. $\mathrm{mL}^{-1}$; controls 63 (4-180) $\mathrm{ng} \cdot \mathrm{mL}^{-1} ; \mathrm{p}=0.12$ ) (fig. 2 ). Elastase $/ \alpha_{1}$-antitrypsin complex levels differed between the three groups $(\mathrm{p}=0.014)$, and were higher both in CFA median (range) 2.42 (1.74-3.66) $\mathrm{ng} \cdot \mathrm{mL}^{-1}$ and FASSc $1.8(0.29-8.5) \mathrm{ng} \cdot \mathrm{mL}^{-1}$ than controls $0.57(0.46-0.81) \mathrm{ng} \cdot \mathrm{mL}^{-1}(\mathrm{FASSc}, \mathrm{p}=0.027$; CFA, $\mathrm{p}=0.006$ ) (fig. 3).

Secondary granules. Collagenase activity was detectable in $40 \%$ (6 out of 15 ) of patients with CFA, compared with $15 \%$ (3 out of 20) of those with FASSc and none of the controls $(\mathrm{p}=0.024)$ (fig. 4). Levels were higher in CFA (range 0-480 $\mathrm{m}$ units) than both FASSc $(0-60 \mathrm{~m}$ units, $\mathrm{p}=0.048)$ and controls $(\mathrm{p}=0.026)$, indicating significant release of the contents of secondary granules in CFA. Levels of collagenase in FASSc and controls were

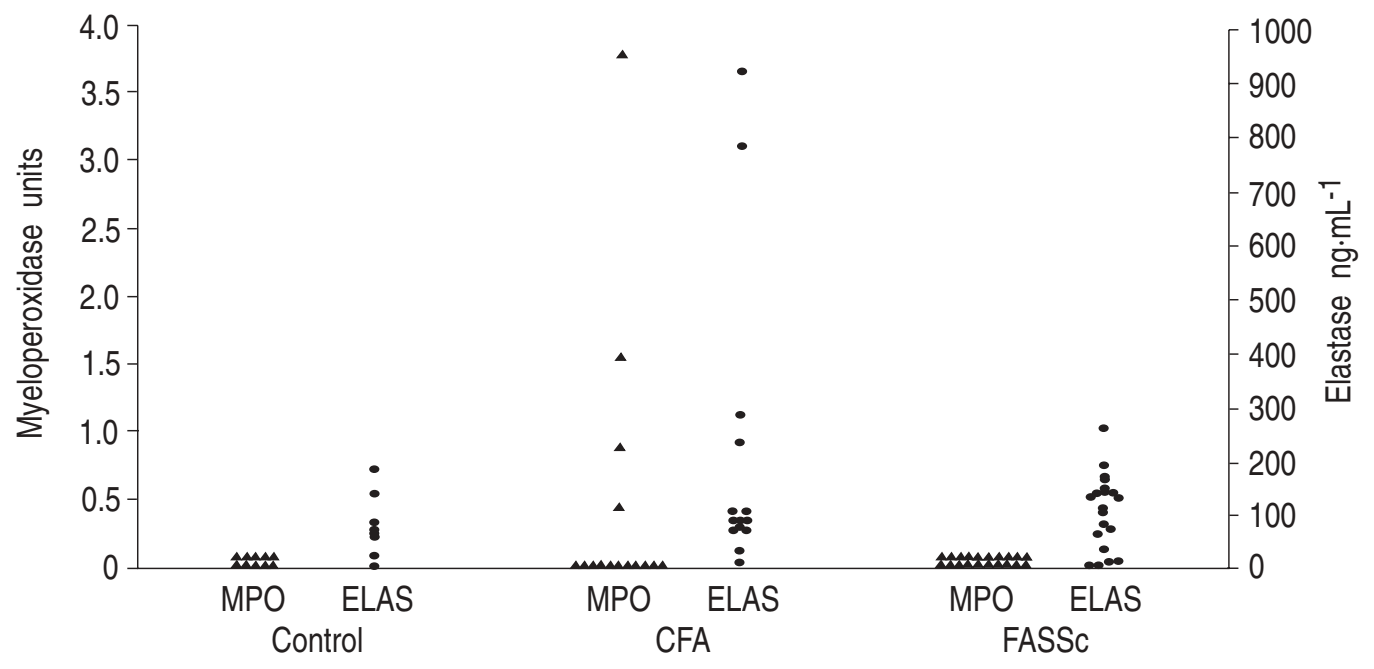

Fig. 2. - Levels of primary granule enzymes myeloperoxidase (MPO) and elastase (ELAS) compared between patients with FASSc and CFA and Controls. MPO activity was found only in CFA patients. Elastase levels were similar across the groups. For abbreviation see legend to figure 1. 


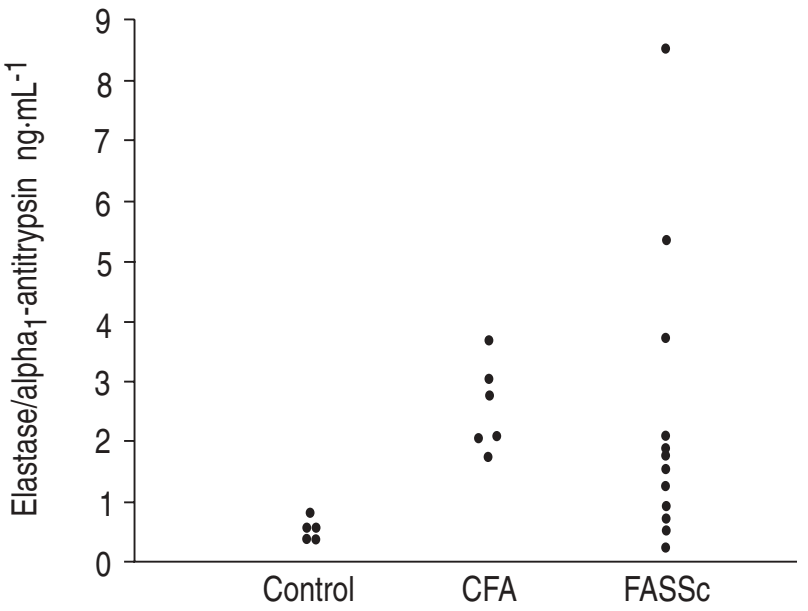

Fig. 3. - Elastase $/ \alpha_{1}$-antitrypsin complex levels in patients with FASSc and CFA and Controls. Both CFA and FASSc patients had significantly higher levels than controls. For abbreviations see legend to figure 1 .

comparable $(\mathrm{p}=0.20)$. BAL fluid LF levels did not differ between the three groups (CFA median (range) 0.12 $(0.03-2.64) \mathrm{ng} \cdot \mathrm{mL}^{-1} ;$ FASSc $0.17(0.03-1.08) \mathrm{ng} \cdot \mathrm{mL}^{-1}$; controls $\left.0.06(0.05-0.3) \mathrm{ng} \cdot \mathrm{mL}^{-1} ; \mathrm{p}=0.33\right)$ (fig. 4). All patients with measurable MPO levels also had elevated collagenase levels although there was no quantitative relationship between the two. There was, however, a direct relationship between MPO and elastase levels. To ensure that the increased levels of MPO and collagenase were not due to plasma leak, results were standardized for BAL fluid albumin levels (data not shown). The significant differences between the groups for both enzymes remained after standardization, confirming that plasma leak was not an important factor in the raised enzyme levels.

\section{Enzyme level relationship with smoking and treatment}

As both treatment of fibrosing alveolitis and cigarette smoking can alter neutrophil numbers in BAL, association was sought between these variables and levels of neutrophil enzymes. Enzyme levels were similar in subjects who had ever smoked and lifetime nonsmokers and in treated patients compared to nontreated, suggesting that they did not exert a significant effect on neutrophil enzyme release. Of the nine patients with samples positive for either MPO or collagenase, six were on no treatment compared to 13 of 26 patients with neither MPO nor collagenase in the lavage fluid.

Relationship between neutrophil counts and enzyme activity

The relationship between BAL neutrophil numbers and enzyme levels was assessed to determine whether migration of neutrophils to the lung was associated with their activation. As the majority of BAL samples did not show evidence of either collagenase or MPO activity they were analysed on the basis of whether or not there was evidence of: 1) collagenase; and 2) MPO in BAL fluid; neutrophil numbers compared between the two groups. Neutrophil percentage counts (median (range)) were significantly higher in subjects with evidence of collagenase activity, 24 (1-60)\% compared to those without, $3(0-21) \%(\mathrm{p}=0.0038)$. Similarly, in subjects with evidence of MPO activity, neutrophil percentage counts were increased, 41 (19-60)\% compared to $3(0-24) \%$ in those without BAL MPO $(\mathrm{p}=0.0016)$. Total neutrophil numbers were also significantly higher in the group with MPO activity $(\mathrm{p}=0.02)$, and tended to be higher in those with collagenase activity $(\mathrm{p}=0.075)$.

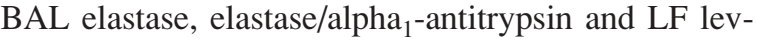
els showed greater variation than collagenase and MPO, and, therefore, the relationship between these enzyme concentrations and neutrophil numbers was assessed (fig. 5). Elastase and elastase $/ \alpha_{1}$-antitrypsin complex levels correlated significantly with neutrophil percentage $(r=0.400, p=0.002$; and $r=0.59, p=0.005$, respectively $)$ and similar significant correlations were found with total neutrophil numbers. LF levels correlated less well with neutrophil percentages and numbers $(r=0.16$, NS; and $r=0.19$, NS, respectively).

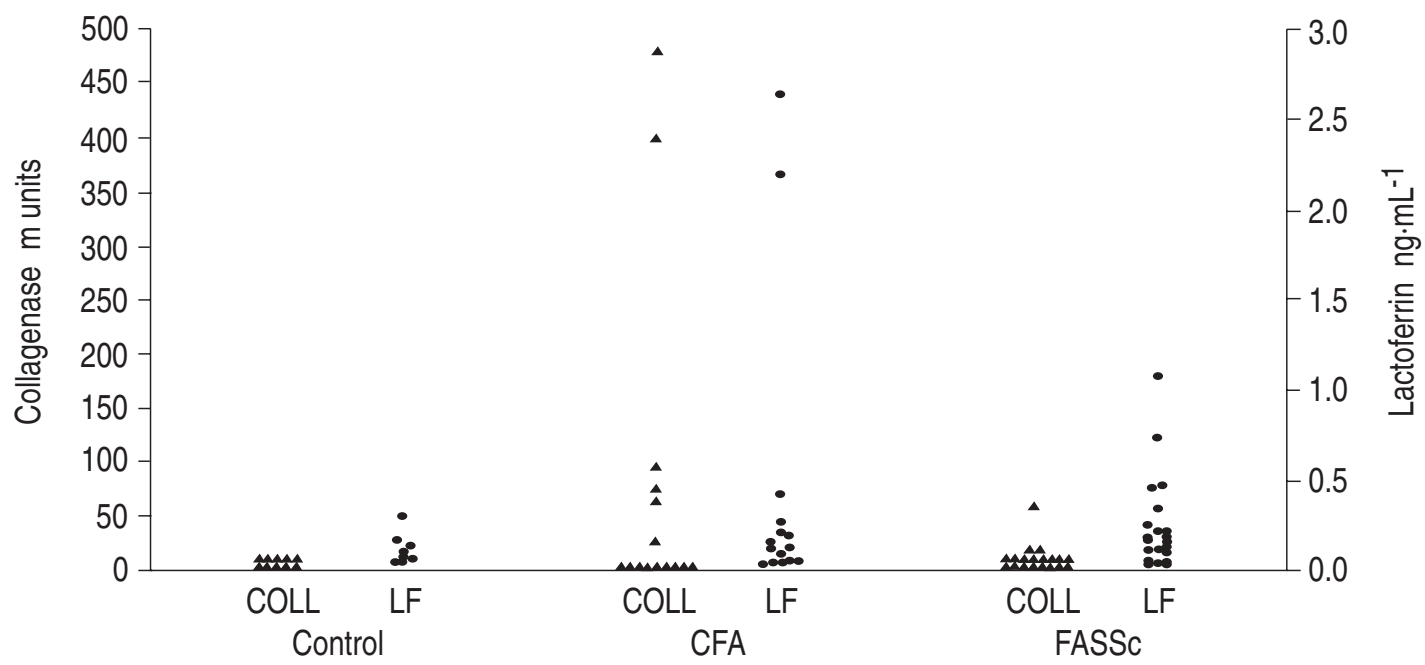

Fig. 4. - Neutrophil secondary granule enzymes compared in patients with FASSc and CFA and Controls. Collagenase (COLL) levels in CFA are higher than both controls and FASSc. Levels in FASSc are similar to those in controls. Lactoferrin (LF) levels are similar across the groups. For abbreviations see legend to figure 1 . 
a)

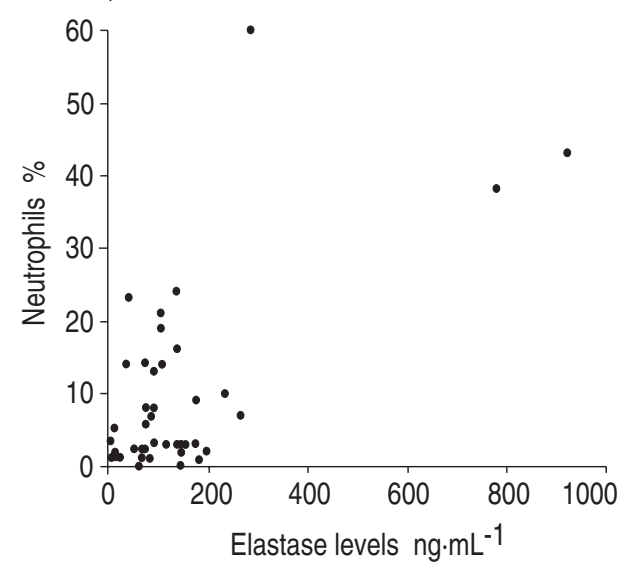

b)

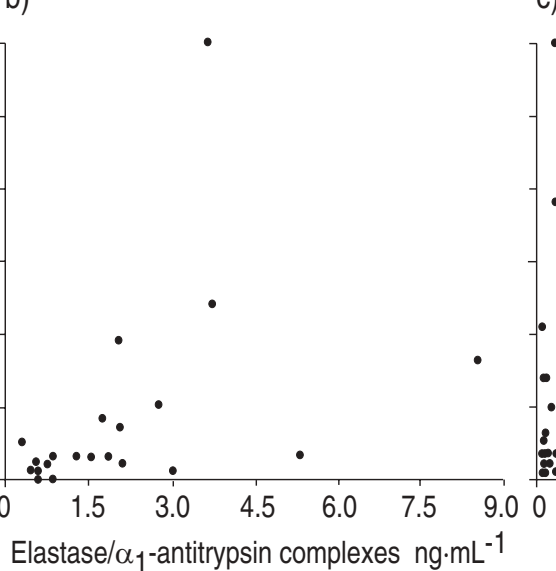

c)

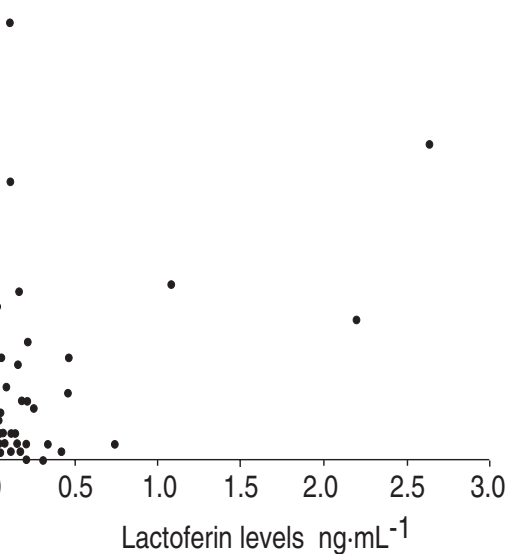

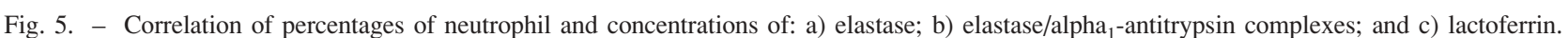

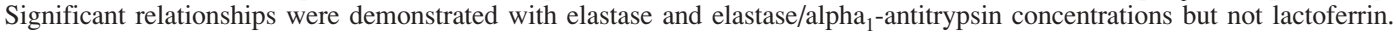

\section{Neutrophil enzyme release and lung function in CFA and FASSc}

Neutrophil enzymes can damage pulmonary parenchyma and, consequently, depress lung function indices. To relate concentrations of enzymes to lung function, FA patients were separated into two groups depending on enzyme levels. Neutrophil activation was considered present if any enzyme level was greater than 2 standard deviations above the control average. Evidence of neutrophil activation was associated with a significantly lower FVC (percentage predicted) $(\mathrm{p}<0.004)$ (fig. 6), supporting the concept that neutrophil degranulation products are associated with amplification of lung injury.

To ensure that the association between neutrophil activation and depression of FVC was not due to other factors which commonly affect lung function, multiple linear regression analysis was performed with FVC percentage predicted as the dependent variable, and the variables, age, sex, disease type, duration of dyspnoea (as a marker of disease duration), pack-years smoked (log), and state of neutrophil activation as independent explanatory variables. Only the presence or absence of neutrophil activation was independently predictive of FVC, neutrophil activation being associated with a significantly lower FVC $(p=0.017)$. Gas transfer was lower in the group with evidence of neutrophil activation (median 43.5 vs $50.3 \%$ pred) but this did not reach statistical significance $(\mathrm{p}=0.15)$.

Correlations of FVC and TL,CO with individual enzyme concentrations were also significant for elastase concentrations (FVC r=-0.40, p<0.01; TL,CO r=-0.38, $\mathrm{p}<0.025)$ and lactoferrin concentrations (TL,CO $\mathrm{r}=-0.29, \mathrm{p}<0.05)$ (data not shown).

\section{Discussion}

Fibrosing alveolitis occurring as a lone disease (cryptogenic fibrosing alveolitis), and fibrosing alveolitis associated with systemic sclerosis have been considered to be identical due to radiological and pathological similarities, and it has been assumed that the prognosis is the same. Our previous studies have demonstrated that this

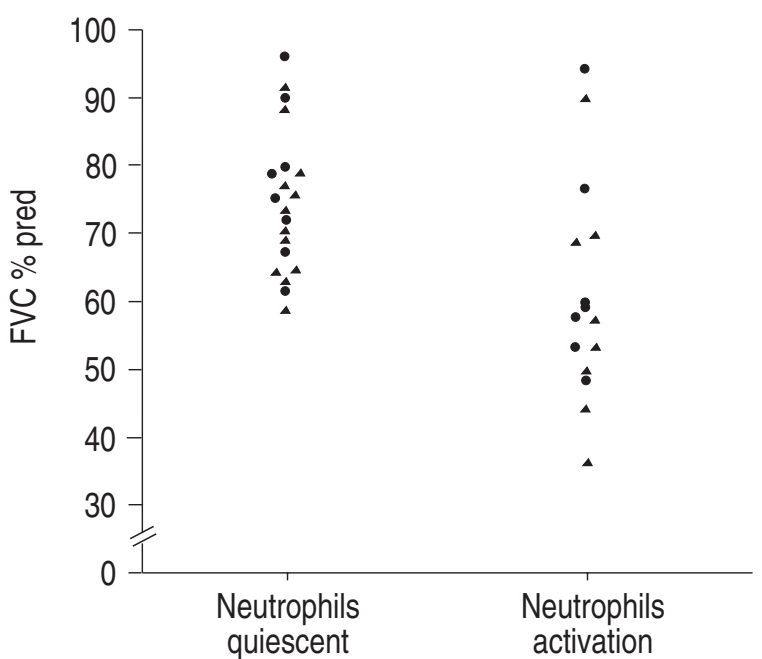

Fig. 6. - Forced vital capacity (FVC) related to the presence or absence of neutrophil activation in patients with fibrosing alveolitis. FVC was depressed to a significantly greater degree in patients with evidence of neutrophil activation independent of patient age, sex, disease, duration of dyspnoea and pack-years smoked. $\mathbf{\Delta}$ : FASSc; CFA. For abbreviations see legend to figure 1 .

is not the case [12]. In this study, we have shown increased amounts of potentially destructive neutrophil enzymes in BAL fluid in CFA than in FASSc or controls. Significant differences were seen in BAL neutrophil numbers and the activity of the enzymes collagenase and MPO between CFA and FASSc despite similar depression in lung function indices, which suggests that differences in neutrophil migration and activation may be of relevance to disease outcome. We speculate that chemotaxis and activation of neutrophils is under different control in these two disorders and that enhanced neutrophil activity is likely to be a major factor determining the relatively poor prognosis of patients with CFA.

The neutrophil in the pathogenesis of fibrosing alveolitis

It has long been recognized that the presence of increased numbers of neutrophils in BAL fluid in CFA is associated with extensive disease and a poor prognosis [1-4]. 
A similar association of increased BAL fluid neutrophils and clinical activity has been reported in FASSc. In this regard, individuals with FASSc and increased BAL fluid neutrophils have been shown to have greater depression of lung function and increased radiographic abnormality on chest radiography [22]. More recently, our group found a relationship between BAL neutrophil numbers and the extent of disease in the lavaged lobe (assessed by CT) [1], providing further support for the hypothesis that neutrophils are associated with more severe disease. The mechanism by which the neutrophil may exert a damaging effect on the lung parenchyma is through a combination of release of damaging enzymes and the generation of reactive oxygen species, and several reports of human studies are consistent with this [10, 13, 14, 23, 24].

\section{Neutrophil enzymes in fibrosing alveolitis}

The release of damaging neutrophil enzymes into the extracellular space is a feature common to many lung diseases characterized by fibrosis, including CFA, sarcoidosis, fibrosing alveolitis complicating rheumatoid disease, and the adult respiratory distress syndrome [13, 25-32]. However, this has not been assessed previously in FASSc. Our findings of increased concentrations of collagenase and MPO in lavage fluid from individuals with CFA strengthens the evidence that these enzymes are involved in the pathogenesis of pulmonary fibrosis. We have, in addition, shown that free enzymes are present in the lower respiratory tracts of patients with FASSc.

Elastase activity was not increased in either CFA or FASSc and suggests a limited role for this enzyme in the pathogenesis of these conditions. However, our findings of increased amounts of elastase/alpha ${ }_{1}$-antitrypsin complexes in CFA and FASSc suggests that elastase has been released by neutrophils at disease sites, but has subsequently been inactivated within the local milieu. Whether released NE has already damaged the delicate microenvironment prior to inactivation is unknown but, in this regard, the tight apposition of neutrophil to substrate, thereby impeding access to alpha $_{1}$-antitrypsin, may provide some support for this speculation.

In FASSc collagenase and MPO were found in few patients. This is in contrast to the situation in CFA, suggesting that differential neutrophil activation may be one key mechanism responsible for the better prognosis seen in this condition. A lesser burden of destructive enzymes within the lower respiratory tract is likely to equate to a slower rate of progression of parenchymal damage, and ultimately, a survival advantage.

\section{Relationship of neutrophil activity to lung function}

Considering the number of enzymes with the potential to damage lung tissue contained in neutrophil granules, it is unlikely that the pulmonary parenchymal damage seen in fibrosing alveolitis is due to the action of any single enzyme. Rather, the combined effects both of proteolytic enzymes and enzymes involved in production of oxygen radicals are likely to cause parenchymal damage. Accordingly, we categorized patients on the basis of increased levels of any of the four enzymes measured. Neutrophil activation was considered present if the level of any enzyme was greater than two standard deviations above the mean control value. The hypothesis that the neutrophil has a pivotal role in mediation of parenchymal damage in FA is supported by the strong association between BAL fluid neutrophil activation and depression of vital capacity in patients with FA. This association was independent of other factors which could confound the relationship between neutrophil enzyme release and pulmonary function, further strengthening the concept that the neutrophil has a significant role in the progression of injury in fibrosing alveolitis. A similar association between BAL neutrophil enzymes and depression of lung function indices has been found in sarcoidosis [29].

\section{Differential neutrophil traffic and activation: CFA ver- sus FASSc}

We have shown that the activity of collagenase and MPO in lavage fluid differs between two diseases with histologically identical fibrosing alveolitis. The reasons for this difference demand further investigation as they may help explain the prognostic survival advantage seen in FASSc. Interleukin-8, a chemokine produced primarily by cells of the monocyte/macrophage lineage, is a potent and selective chemoattractant and activator of neutrophils. There is constitutive expression of IL- 8 messenger ribonucleic acid (mRNA) in the lower respiratory tract of patients with CFA, and the amount of IL-8 in macrophages from patients with CFA is higher than in normal subjects $[6,9,33]$. In CFA, raised IL-8 mRNA levels are associated both with higher BAL neutrophil counts and greater disease severity [6]. Results from our group have recently confirmed this and demonstrated significantly higher levels of BAL fluid IL-8 in CFA than FASSc [9]. We suggest that in FASSc, lower production of IL-8 leads both to lower neutrophil numbers and decreased release of neutrophil-derived enzymes in the lower respiratory tract.

Under normal circumstances, the production and release of neutrophil enzymes is under strict control, limiting proteolysis of the extracellular matrix to that which is required for normal tissue remodelling and repair. The excessive activity of collagenase and MPO seen in CFA may be due either to excess release of these enzymes or to deficiency of enzyme inhibitors (or a combination of the two). Data are lacking on the amount and functional adequacy of enzyme inhibitors in FA. Indirect evidence that augmentation of the action of enzyme inhibitors may have a beneficial effect comes from animal models. In the hamster, infused alpha ${ }_{1}$-antitrypsin significantly attenuates the development of bleomycin-induced lung fibrosis, but the mechanism of this effect is unclear [34]. Possible therapeutic roles for other inhibitors of neutrophil enzymes, such as the tissue inhibitors of metaloproteases, are yet to be elucidated.

In summary, we have demonstrated significant differences in the activity in bronchoalveolar lavage fluid of enzymes both from primary and secondary neutrophil granules in cryptogenic fibrosing alveolitis compared with fibrosing alveolitis complicating systemic sclerosis and normal controls. Evidence of neutrophil activation and enzyme release is associated with lung function impairment, supporting the hypothesis that the neutrophil has a key role in the pathogenesis of fibrosing alveolitis. 
Comparing the features of cryptogenic fibrosing alveolitis with fibrosing alveolitis complicating systemic sclerosis is likely to offer further insights into the pathogenesis of fibrosing alveolitis.

\section{References}

1. Wells AU, Hansell DM, Rubens MB, et al. Fibrosing alveolitis in systemic sclerosis: bronchoalveolar lavage findings in relation to computed tomographic appearance. Am J Respir Crit Care Med 1994; 150: 462-468.

2. Turner-Warwick M, Haslam PL. The value of serial bronchoalveolar lavages in assessing the clinical progress of patients with cryptogenic fibrosing alveolitis. Am Rev Respir Dis 1987; 135: 26-34.

3. Haslam PL, Turton CW, Lukoszek A, et al. Bronchoalveolar lavage fluid cell counts in cryptogenic fibrosing alveolitis and their relation to therapy. Thorax 1980; 35: 328-339.

4. Watters LC, Schwarz MI, Cherniack RM, et al. Idiopathic pulmonary fibrosis: pretreatment bronchoalveolar lavage cellular constituents and their relationships with lung histopathology and clinical response to therapy. Am Rev Respir Dis 1987; 135: 696-704.

5. Car BD, Meloni F, Luisetti M, Semenzato G, GialdroniGrassi G, Walz A. Elevated IL-8 and MCP-1 in the bronchoalveolar lavage fluid of patients with idiopathic pulmonary fibrosis and pulmonary sarcoidosis. Am J Respir Crit Care Med 1994; 149: 655-659.

6. Carre PC, Mortenson RL, King TE Jr, Noble PW, Sable $\mathrm{CL}$, Riches DW. Increased expression of the interleukin8 gene by alveolar macrophages in idiopathic pulmonary fibrosis: a potential mechanism for the recruitment and activation of neutrophils in lung fibrosis. J Clin Invest 1991; 88: 1802-1810.

7. Standiford TJ, Rolfe MW, Kunkel SL, et al. Macrophage inflammatory protein- $1 \alpha$ expression in interstitial lung disease. J Immunol 1993; 151: 2852-2863.

8. Ozaki T, Hayashi H. Tani K, Ogushi F, Yasuoka S, Ogura T. Neutrophil chemotactic factors in the respiratory tract of patients with chronic airway diseases or idiopathic pulmonary fibrosis. Am Rev Respir Dis 1992; 145: 85-91.

9. Southcott AM, Jones KP, Li D, et al. Interleukin-8 and fibrosing alveolitis: differential expression in lone fibrosing alveolitis and fibrosing alveolitis in systemic sclerosis. Am J Respir Crit Care Med 1995; 151: 1604-1612.

10. Crystal RG, Bitterman PB, Rennard ST, Hance AJ, Keogh BA. Interstitial lung diseases of unknown cause: disorders characterized by chronic inflammation of the lower respiratory tract. N Engl J Med 1984; 310: 154-165 and 235-244.

11. Harrison NK, Myers AR, Corrin B, et al. Structural features of interstitial lung disease in systemic sclerosis. Am Rev Respir Dis 1991; 144: 706-713.

12. Wells AU, Cullinan P, Hansell DM, et al. Fibrosing alveolitis associated with systemic sclerosis has a better prognosis than lone cryptogenic fibrosing alveolitis. Am J Respir Crit Care Med 1994; 149: 1583-1590.

13. Gadek JE, Kelman JA, Fells GA, et al. Collagenase in the lower respiratory tract of patients with idiopathic pulmonary fibrosis. N Engl J Med 1979; 301: 737-742.

14. Hallgren R, Bjermer L, Lundgren R, Venge P. The eosinophil component of the alveolitis in idiopathic pulmonary fibrosis: signs of eosinophil activation in the lung are related to impaired lung function. Am Rev Respir Dis 1989; 139: 373-377.

15. Subcommittee for Scleroderma Criteria of the American
Rheumatism Association Diagnostic Therapeutic Criteria Committee. Preliminary criteria for the classification of systemic sclerosis (scleroderma). Arthritis Rheum 1980; 23: 581-590.

16. Metcalf JA, Gallin JI, Nauseef WM, Root RK. Laboratory manual of neutrophil function. New York, Raven Press, 1986; pp. 150-151.

17. O'Connor CM, Gaffney K, Keane J, et al. Alpha 1 -proteinase inhibitor, elastase activity, and lung disease severity in cystic fibrosis. Am Rev Respir Dis 1993; 148(1): $1665-1670$.

18. Gisslow MT, McBride BC. A rapid and sensitive collagenase assay. Anal Biochem 1975; 68: 70-78.

19. Kolsto-Otnaess AB, Meberg A, Sande HE. Plasma lactoferrin measured by an enzyme-linked immunosorbent assay (ELISA). Scand J Haematol 1983; 31: 235-240.

20. Denison DM, Cramer DS, Hanson PJ. Lung function testing and AIDS. Respir Med 1989; 83: 133-138.

21. Reynolds HY. Bronchoalveolar lavage. Am Rev Respir Dis 1987; 135: 250-263.

22. Silver RM, Miller KS, Kinsella MB, Smith EA, Schabel SI. Evaluation and management of scleroderma lung disease using bronchoalveolar lavage. Am J Med 1990; 88: 470-476.

23. Behr J, Maier K, Krombach F, Adelmann-Grill BC. Pathogenetic significance of reactive oxygen species in diffuse fibrosing alveolitis. Am Rev Respir Dis 1991; 144: 146-150.

24. Maier K, Leuschel L, Costabel U. Increased levels of oxidized methionine residues in bronchoalveolar lavage fluid proteins from patients with idiopathic pulmonary fibrosis. Am Rev Respir Dis 1991; 143: 271-274.

25. O'Connor C, Odlum C, van Breda A, Power C, FitzGerald MX. Collagenase and fibronectin in bronchoalveolar lavage fluid in patients with sarcoidosis. Thorax 1988; 43: 393-400.

26. Christner P, Fein A, Goldberg S, Lippmann M, Abrams $\mathrm{W}$, Weinbaum G. Collagenase in the lower respiratory tract of patients with adult respiratory distress syndrome. Am Rev Respir Dis 1985; 131: 690-695.

27. Gilligan DM, O'Connor CM, Ward K, Moloney D, Bresnihan B, FitzGerald MX. Bronchoalveolar lavage in patients with mild and severe rheumatoid lung disease. Thorax 1990; 45: 591-596.

28. Idell S, Kucich U, Fein A, et al. Neutrophil elastasereleasing factors in bronchoalveolar lavage from patients with adult respiratory distress syndrome. Am Rev Respir Dis 1985; 132: 1098-1105.

29. Ward K, O'Connor CM, Odlum C, Power C, FitzGerald MX. Pulmonary disease progress in sarcoid patients with and without bronchoalveolar lavage collagenase. Am Rev Respir Dis 1990; 142: 636-641.

30. Weiland JE, Garcia JG, Davis WB, Gadek JE. Neutrophil collagenase in rheumatoid interstitial lung disease. $J$ Appl Physiol 1987; 62: 628-633.

31. Gadek JE. Adverse effects of neutrophils on the lung. Am J Med 1992; 92: 27S-31S.

32. O'Connor CM, FitzGerald MX. Matrix metalloproteases and lung disease. Thorax 1994; 49: 602-609.

33. Lynch JP, Standiford TJ, Rolfe MW, Kunkel SL, Strieter RM. Neutrophilic alveolitis in idiopathic pulmonary fibrosis: the role of interleukin-8. Am Rev Respir Dis 1992; 145: 1433-1439.

34. Nagai A, Aoshiba K, Ishihara Y, et al. Administration of alpha ${ }_{1}$-proteinase inhibitor ameliorates bleomycininduced pulmonary fibrosis in hamsters. Am Rev Respir Dis 1992; 145: 651-656. 